\title{
CONVERGÊNCIA ENTRE A COMUNICAÇÃO DIGITAL E A PRÁTICA DA EDUCAÇÃO A DISTÂNCIA
}

Andréia de Bem Machado ${ }^{1}$ Andreza Regina Lopes da Silva ${ }^{2}$ Araci Hack Catapan ${ }^{3}$

\section{RESUMO}

A sociedade contemporânea caminha no cerne de uma realidade em que a tecnologia disruptiva vem dominando um novo modo de fazer educação. Uma educação virtual em que a comunicação se faz presente, por diferentes meios e espaços, num movimento em ascendência tecnológica. Neste artigo, o objetivo é convergir a comunicação digital com a prática da Educação a Distância. Para atender a esse objetivo, a metodologia utilizada foi a análise bibliométrica da literatura científica organizada em base de dados online. Como resultado identificou-se a escassez de publicações, empíricas e teóricas, que explicitem a convergência da comunicação digital com a prática de fazer educação na modalidade a distância, indicando, assim, proeminência quanto à necessidade de pesquisas sobre a ontologia do termo comunicação digital - e a relação deste com as práticas de um outro modo de se fazer educação uma Educação a Distância.

Palavras-Chave: Comunicação digital. Educação a Distância. Bibliometria. 


\section{INTRODUÇÃO}

As possibilidades dos recursos cada vez mais interativos no cenário da educação têm alterado a concepção de sua prática.A tecnologia contribui para o acesso ao conhecimento que vem se ampliando por meio das redes de comunicação digital. Os inúmeros caminhos assumidos por uma tecnologia disruptiva apontam para diferentes realidades no processo de ensino-aprendizagem, vislumbram uma educação virtual que vai além da sala de aula.

\section{As ATIVIDADES RELACIONADAS}

À EDUCAÇÃO TÊM SE AMPLIADO

PELOS DIFERENTES MEIOS DE COMUNICAÇÃO POSSIBILITADOS,

ORA PELA TECNOLOGIA ANALÓ-

GICA, ORA PELA TECNOLOGIA

Digital. No mOdo ANALÓGICO,

A COMUNICAÇÃO TRAFEGA POR

ONDAS ELETROMAGNÉTICAS, PO-

DENDO SER AFETADA POR OUTROS

CAMPOS ELÉTRICOS, QUE PODEM

COMPROMETER A QUALIDADE

DO SINAL. JÁ NO MODO DIGITAL,

A COMUNICAÇÃO NAVEGA POR

BITS BINÁRIOS QUE, ALÉM DE

SER UM MEIO MAIS RÁPIDO, PRO-

PORCIONA MAIOR QUALIDADE E CONFIABILIDADE.

A palavra "digital" vem de dígito que, por sua vez, vem do latim digitus, que procede de dedos, fazendo uma relação direta aos números inteiros até dez - dez dedos - como um processo de contagem. (CUNHA, 2010).
A comunicação impulsionada pela expansão da internet tem ganhado o espaço para possibilitar uma educação de qualidade a diferentes públicos, em diferentes lugares e espaços. De acordo com os Referenciais de Qualidade da Educação a Distância (EaD), a comunicação potencializa o princípio da interação e da interatividade, fundamental para a educação e, por isso, deve ser garantida por meio da disponibilização e do uso de diferentes recursos tecnológicos. (BRASIL, 2007).

A concepção e a prática de um projeto educacional, ofertado na modalidade a distância, requer diferentes atenções, entre as quais se destacam: os artefatos que proporcionam a comunicação para a efetividade e o sucesso do projeto. A comunicação inerente ao processo de ensino-aprendizagem deve ser ampliada e diversificada constantemente, de acordo com as características e necessidades do público a ser atendido.

\section{Recursos, como o Ambiente Virtual de Ensino-Aprendizagem (AVEA), têm contribuído para situações antes inexisten- tes no cenário educacional, como a acessi- bilidade ao processo de construção do conhecimento.}

Entende-se, neste artigo, AVEA como um espaço virtual de comunicação digital para o compartilhamento e a disseminação do conhecimento por meio da interação num movimento de aprendizagem.

Inerente a essa reflexão, pergunta-se: qual a relação da comunicação digital com a Educação a Distância? A partir desta problemática, o objetivo deste artigo, ao responder à questão, é 
mapear as publicações científicas que discutem a relação da comunicação digital com a $\mathrm{EaD}$, de modo a contribuir com estudos na área e tomadas de decisões que orientem projetos educacionais na modalidade a distância.

\section{A partir da ressignificação do processo ensino-aprendizagem, adquire-se um novo modo do ser, do saber e do aprender para além da sala de aula, em que os processos passam a explorar a tecnologia da comuni- cação digital. (CATAPAN, 2002a).}

Para Catapan (2002b), uma comunicação por meio da linguagem digital implica diferentes formas de comunicar, perpassando a oralidade, a escrita, a imagem, o som, o colorido, as ações, as emoções.

$\mathrm{Na}$ sociedade atual, comunicar exige um novo conceito, uma nova prática que vai além da sala de aula, além da sala familiar e além da sala instituição. Transcende limites geográficos e temporais. Avança numa perspectiva de rede, o que requer elementos diferenciados do modo de comunicação tradicional.A comunicação digital potencializada pelas diferentes tecnologias e mídias influencia na forma com a qual o sujeito se relaciona com a sociedade em que vive.

\section{A comunicação digital permite que o ensinar e o aprender sejam uma ação interconectada, difusa, interdisciplinar, podendo ser considerada, no século XXI, uma prática natural que permite novas formas de construção do conhecimento.}

Uma comunicação que se expande não respondendo especificamente ao modelo tradicional em que emissor e receptor trocam informações, mas sim uma comunicação em que emissor e receptor sejam participantes ativos com autonomia para emitir e receber um comunicado, posicionando-se criticamente ou ressignificando-o. A comunicação é um processo, na sociedade globalizada, e não um produto acabado. Um processo que deve ir além da transmissão de uma mensagem, pois a comunicação deve possibilitar o "partilhar sentido" (LÉVY, 1996). Segundo este autor, um processo de virtualização que atinge o estar junto.

$\mathrm{Na}$ EaD, a comunicação ocorre sem espaço e tempo definido.

$$
\begin{aligned}
& \text { A educação virtual [...] está exposta } \\
& \text { na tela do computador [...] local em } \\
& \text { que se partilham fluxos e mensa- } \\
& \text { gens para a difusão dos saberes [...] } \\
& \text { construindo novas formas de comu- } \\
& \text { nicação, o espaço da escola virtual } \\
& \text { se apresenta pela estruturação de } \\
& \text { comunidades online em que alunos } \\
& \text { e professores dialogam permanente- } \\
& \text { mente, mediados pelos conhecimen- } \\
& \text { tos. (KENSKI, 2004, p. 55). }
\end{aligned}
$$

Mudanças como essas implicam um novo modo de fazer a educação. Afetam o sistema tradicional de ensino, instigando novas práticas educacionais em que os envolvidos no processo de ensino-aprendizagem possam se sentir parte do processo. Brasil (2007) corrobora que as mudanças no cenário educacional podem ser justificadas em razão das alterações provocadas por diferentes fatores, dos quais se destacam: o sistema de comunicação infere em diferentes possibilidades de mediação pedagógicas. Nesse sentido, considera-se que o projeto educacional, principalmente na modalidade a distância, precisa prever diferentes meios de comunicação para atender às diferentes necessidades comunicacionais de seus atores. É preciso criar condições para potencializaruma aprendizagem significativa que não é resultado do ensinar, mas sim do aprender com significado. 


\section{REVISÃO BIBLIOMÉTRICA: UMA DESCRIÇÃO}

Bibliometria não é um termo novo, apesar de se notar ainda a baixa intensidade de seu uso quando analisado em âmbito macro nas pesquisas científicas. Contudo, de acordo com Santos e Kobashi (2009), foi a partir do século XX que esse método ganhou densidade e legitimidade.

A bibliometria é uma metodologia oriunda das ciências da informação e consiste em métodos matemáticos e estatísticos para pesquisar e analisar documentos resultantes de publicação (FEATHER; STURGES, 2003). Para os autores, a bibliometria pode ser dividida em análise avaliativa e/ou descritiva, sendo ambos possíveis de contagens relevantes como produção por região, temporalidade ou área do conhecimento, contagem de literatura relacionada à citação do estudo, fator de impacto de uma publicação científica, entre outras análises. A bibliometria permite reconhecer o estado da arte de determinado tema em estudo.

\author{
O MAPEAMENTO DA PRODUÇÃO \\ CIENTÍfiCA, EM DETERMINADA \\ ÁREA DO SABER, CONTRIBUI \\ PARA QUE O PESQUISADOR SE \\ POSICIONE CRITICAMENTE A \\ RESPEITO DE SEU OBJETO DE \\ ESTUDO.
}

Diferentemente da revisão bibliográfica tradicional, sem método definido, difere principalmente pela organização da busca que ocorre de modo planejado e sistematizado, o que contribui para minimizar possíveis vieses numa pesquisa, seja esta de cunho teórico ou empírico. A partir desse olhar, definiu-se para esta pesquisa a análise bibliométrica, resultante de uma busca sistemática da literatura, no intuito de mapear a relação da comunicação digital com a EaD. Para a análise bibliométrica, o trabalho foi organizado sistematicamente em três etapas distintas, como ilustra a figura 1.

Figura 1: Sistemática de busca para análise bibliométrica
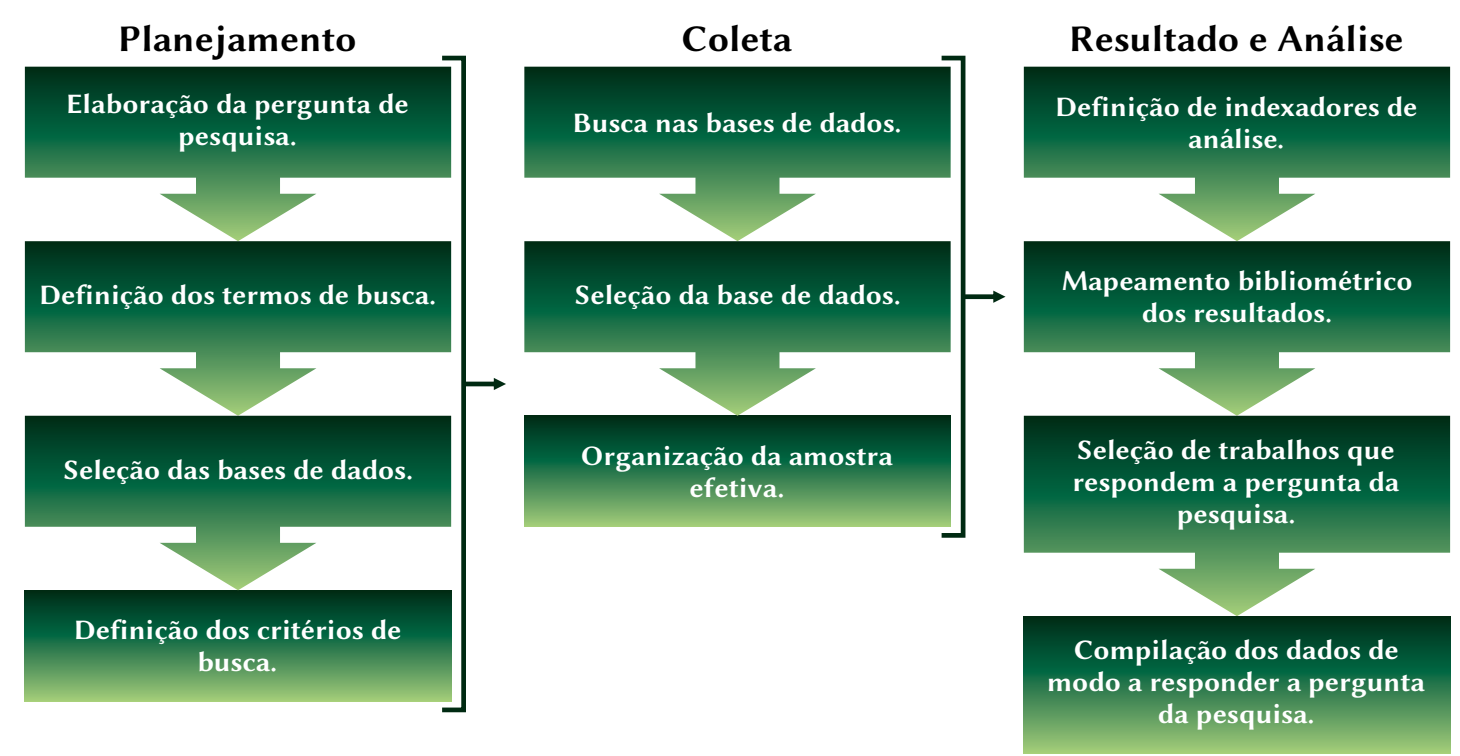

Fonte: Das autoras (2014) 
Essas três etapas ocorrem de modo interconectado, ao longo do processo, para responder a pergunta norteadora da pesquisa e atender ao objetivo proposto no estudo.

\subsection{Planejamento}

Toda pesquisa se inicia com um planejamento. Uma pesquisa científica é planejada a partir de um questionamento base, aqui definido pela pergunta: qual a relação da comunicação digital com a EaD? A partir dessa questão, considerase que o planejamento deve prever a definição dos termos de busca, aqui definidos como: comunicação digital e Educação a Distância.

Dando sequência ao planejamento, define-se a seleção da base de dados para realização da pesquisa, que pode ser analógica - quando realizada em bases, como bibliotecas físicas-, ou pode ser digital - a partir de espaços virtuais de informação, por exemplo, bases de dados online. Pode-se ainda utilizar uma pesquisa integrada que lance mão de recursos analógicos e digitais simultaneamente.

Para elaboração deste artigo, optou-se, inicialmente, pela busca em três bases online. Posteriormente, fez-se a seleção de uma delas para análise em profundidade. $\mathrm{O}$ ponto de partida foi identificar as bases de dados online consideradas relevantes, em consonância com o objetivo de pesquisa. Partiu-se do Portal de
Periódicos da Capes, no qual se considerou fatores como: acessibilidade, visão interdisciplinar e indexação de um número relevante de trabalhos científicos publicados, a partir de revisão por pares, na área em estudo.

Com base nesses critérios, selecionou-se para pesquisa inicial três bases de dados, a saber: Scopus, Educational Resources Information Center(ERIC)e Scielo.A Scopus foi selecionada devido a sua relevância no meio acadêmico,na área de ciências sociais aplicadas. É considerada a maior base de dados, de resumos e de citações de literatura científica, revisada por pares. A escolha da ERIC deu-se devido a sua ênfase na área da educação no intuito de melhorar a prática de aprendizagem. A Scielo foi escolhida por abarcar uma coleção de pesquisas científicas brasileiras.

A partir da seleção das bases de dados para a pesquisa, o passo seguinte foi definir algumas categorias e procedimentos expressos nos termos de busca, aqui organizados em: utilização dos termos de busca em inglês (digital communication; distance education, que, como sinônimo, considerou-se também e-learning e online learning); emprego de dois operadores booleanos (AND e OR); uso de recurso de truncagem, o asterisco $\left(^{*}\right)$, para busca de variações do termo; e uso de aspas para se buscar uma expressão exata na pesquisa. Esse planejamento resultou na combinação ilustrada no quadro 1 .

Quadro 1: Termos-chave utilizados na pesquisa

\begin{tabular}{|c|c|c|}
\hline Termo & Operador booleano & Termos \\
\hline "digital communicatio* technolog*" & AND & $\begin{array}{l}\text { "distance education" OR "e-learning" } \\
\text { OR "online learning" }\end{array}$ \\
\hline \multicolumn{3}{|c|}{ * (asterisco) recurso de truncagem utilizado para recuperar variações de um termo } \\
\hline \multicolumn{3}{|c|}{ ““ “ (aspas) foi utilizada como recurso para buscar uma frase ou expressão exata } \\
\hline
\end{tabular}


Para entender os construtos da pesquisa, sua relação e sua evolução,não houve qualquer recorte temporal nem por tipo de publicação para a análisebibliométrica.Todos os trabalhos selecionados foram mapeados estatisticamente. Outro critério de busca utilizado para selecionar as pesquisas, a partir dos termos-chave, foi trabalhar a partir de campos de indexação, considerados relevantes pelos pesquisadores, como: títulos, resumo e palavras-chave, de acordo com o indexador de cada base, com o intuito de não limitar o resultado. Nas bases de dados Scopus, a busca foi realizada selecionando-se o campo denominado title, abstract e keyword. Na base de dados ERIC, por não permitir a busca em alguns campos específicos, utilizou-se a marcação keywords (allfields), buscando pelos termos-chave em todos os campos. E na base de dados Scielo, optou-se pelo campo "todos os itens", por considerar-se ser este o indexador que contempla o título, as palavras-chave e o resumo das publicações.

\subsection{Coleta}

$\mathrm{Na}$ fase de coleta, fez-se a busca nas bases de dados online, definidas no planejamento, para se identificar a relevância de cada uma das bases pré-selecionadas (Scopus,ERICe Scielo), a partir do número de pesquisas indexadas. $\mathrm{O}$ resultado está mapeado matematicamente na tabela 1 .

Tabela 1: Resultado de indexações por base de dados

\begin{tabular}{|c|c|c|c|}
\hline $\begin{array}{c}\text { Bases de } \\
\text { dados }\end{array}$ & $\begin{array}{c}\text { "digital } \\
\text { communicatio" }\end{array}$ & $\begin{array}{c}\text { "distance education" } \\
\text { OR "e-learning" OR } \\
\text { "online learning" }\end{array}$ & $\begin{array}{c}\text { "digital communicatio*" AND } \\
\text { "distance education" OR "e-lear- } \\
\text { ning" OR "online learning" }\end{array}$ \\
\hline Scielo & 0 & 291 & 0 \\
\hline Scopus & 29.467 & 44.883 & 46 \\
\hline ERIC & 120 & 20.177 & 7 \\
\hline
\end{tabular}

Fonte: Das autoras (2014)

Diante deste resultado, selecionou-se a base de dados Scopus para a construção deste artigo, pois nesta o número de trabalhos que retornou da busca, com os termos "digital communicatio" AND “distanceeducation" OR "e-learning” OR "online learning", totalizou 46 publicações. De posse desse resultado, optou-se trabalhar com a Scopus como campo amostral para análise bibliométrica, realizada no mês de junho de 2014.

Essa fase de coleta se consolidou com a organização da amostra efetiva da pesquisa (46 trabalhos) em um software de gerenciamento de referências, o EndNoteWeb. A escolha dessa ferramenta, desenvolvida pela Thomson Reuters, deu-se pelo conhecimento prévio dos autores quanto aos seus recursos e acesso livre à mesma na versão web, numa proposta de trabalho na nuvem.

Considera-se que um gerenciador de referência contribui com a pesquisa sistemática e com a análise bibliométrica, pois permite a organização de informações relevantes, como: título, autores, ano de publicação, referências completas, atachamento dos documentos selecionados. 


\subsection{Resultado e análise}

A análise bibliométrica dos dados resultante de uma pesquisa sistemática permite ao pesquisador o mapeamento matemático-estatístico das informações científicas encontradas. Para realizar essa análise, considerou-se, para este artigo, os 46 trabalhos encontrados na base de dados Scopus. A partir desses trabalhos, todos escritos na língua inglesa, pôde-se realizar a análise bibliométrica das produções científicas orientadas pelos pontos de convergência entre comunicação digital e EaD. Essa análise foi organizada a partir de seis indicadores de indexação da publicação, selecionados pelos pesquisadores, a saber: distribuição por ano de publicação, tipo de publicação, área de conhecimento das publicações, número de artigos por periódico, número de artigos por autor, instituições com publicações na área e países de maior ocorrência das publicações na problemática deste estudo.
Analisando o ano de publicação dos trabalhos que compõem a amostra da pesquisa, percebese que a publicação na área inicia-se em 1993, seguindo de modo linear e simplificado aolongo dos anos, destacando-se com alguma expressão em 2011 em que aparecem sete documentos publicados, seguidos pelos anos de 2003 e 2012 com cinco documentos. Nos anos de 1993,2006 e 2010, foram publicados quatro documentos. Em 2004, houve a publicação de três trabalhos e nos anos de 1996, 2001, 2007 e 2008 foram publicados dois trabalhos. Já nos anos de 1994, 1997, 2000, 2005, 2009 e 2013 foi publicado apenas um documento. Observa-se ainda a descontinuidade da publicação na área, sendo os anos de 1995, 1998, 1999 e 2002 marcados pela falta de publicação e o ano corrente. Para um melhor entendimento desta descrição e evolução do tema, observa-se o gráfico 1.

Gráfico 1: Distribuição das publicações por ano

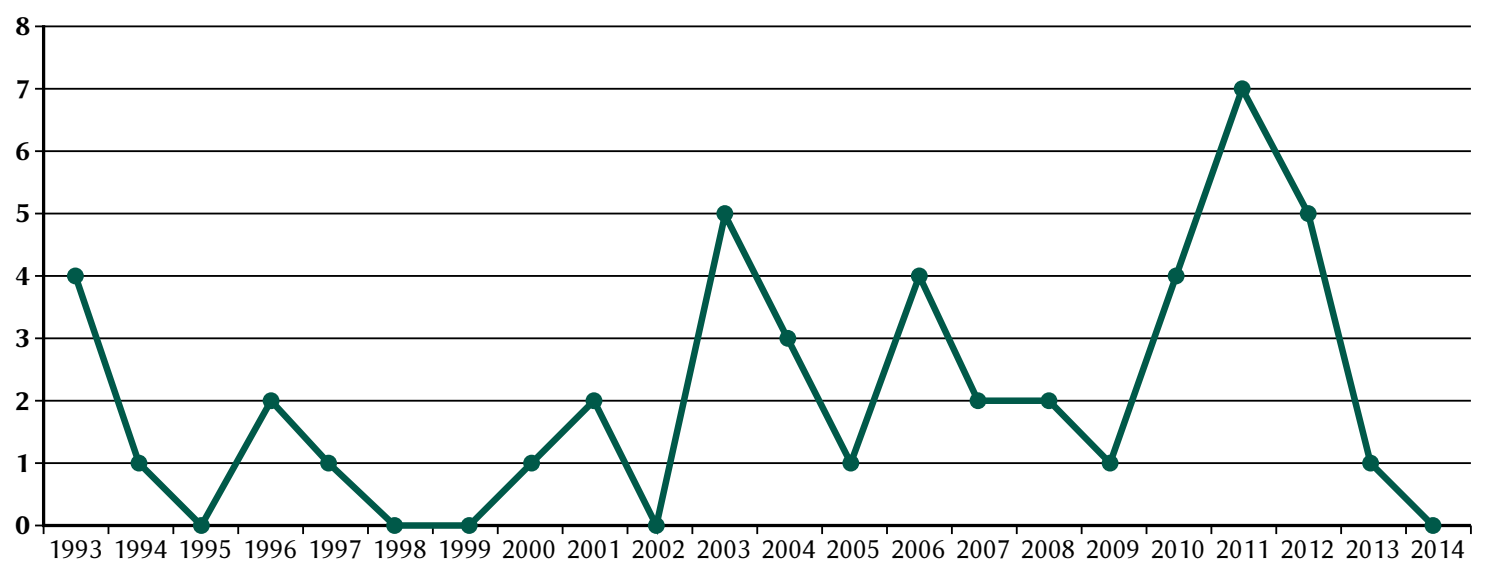

Fonte: Das autoras (2014)

Dando sequência à análise bibliométrica, a partir do resultado da pesquisa, identificou-se que os estudos apresentam-se organizados em: paper de conferência (29), artigos científicos (10), capítulos de livros (1), livros completos (3), revisão de conferência (2) e comentário de conferência (1). Ou seja, 63\% do resultado são trabalhos apresentados em conferência, $22 \%$ são artigos. Os outros documentos foram publicados em formato de livro, revisão de conferência, revisão e capítulo de livro. 
Pôde-se identificar ainda que na área de concentração dos trabalhos publicados tem destaque a Engenharia com 46,9\% seguida da área de Ciências Sociais com 31,3\%, como áreas que se destacam na publicação em que converge a temática pesquisada, ou seja, comunicação digital e EaD. Também há publicações na área das Ciências da Computação com 18,8\% e outras publicações são na área de Matemática e Medicina com 1,6\% do total.

Foi possível ainda ponderar as publicações na ótica dos periódicos essenciais na área. Supõe-se essenciais aqueles que possuem os artigos mais relevantes sobre o tema, que se destacam como fonte de publicação na área. Nessa perspectiva, observou-se que se destacam na publicação anais de eventos e journals: (i) ASEE - uma conferência anual que busca promover o intercâmbio de ideias, melhorando os métodos de ensino e currículo, na área de Engenharia e Tecnologia interessada na educação, com cinco publicações; (ii) IFIP Trasactions A: Computer Science and Technology, um jornal com quatro publicações; (iii) Technologies Applied to Electronics Teaching (TAEE), 2012, uma conferência que representa a atividade de uma rede de professores com o objetivo de refletir sobre o uso de metodologias ativas de aprendizagem, e Proceedings Frontiers in Education Conference, conferência para apresentação e discussão de investigação de excelência educacional e currículos inovadores, no ensino da Engenharia, ambos com três publicações; (iv) IEEE, 2010, uma conferência relacionada ao ensino de Engenharia que em 2010 teve por objetivo identificar os conhecimentos futuros, as competências e habilidades esperadas de graduados em Engenharia por corporações globais orientadas para a tecnologia; (v) ITHEL,2011, Conferência Internacional sobre tecnologia de Ensino Superior baseada na informação e formação; e o (vi) IEE Colloquium Digest, um jornal eletrônico, todos os três com duas publicações cada. Esses eventos e jornals se destacam, em comparação com os demais, num total de 25, que aparecem com apenas uma publicação na área, o que evidencia esta área de pesquisa como não consolidada em periódico ou evento, como mostra o gráfico 2 .

Gráfico 2: Distribuição das publicações por periódicos e eventos

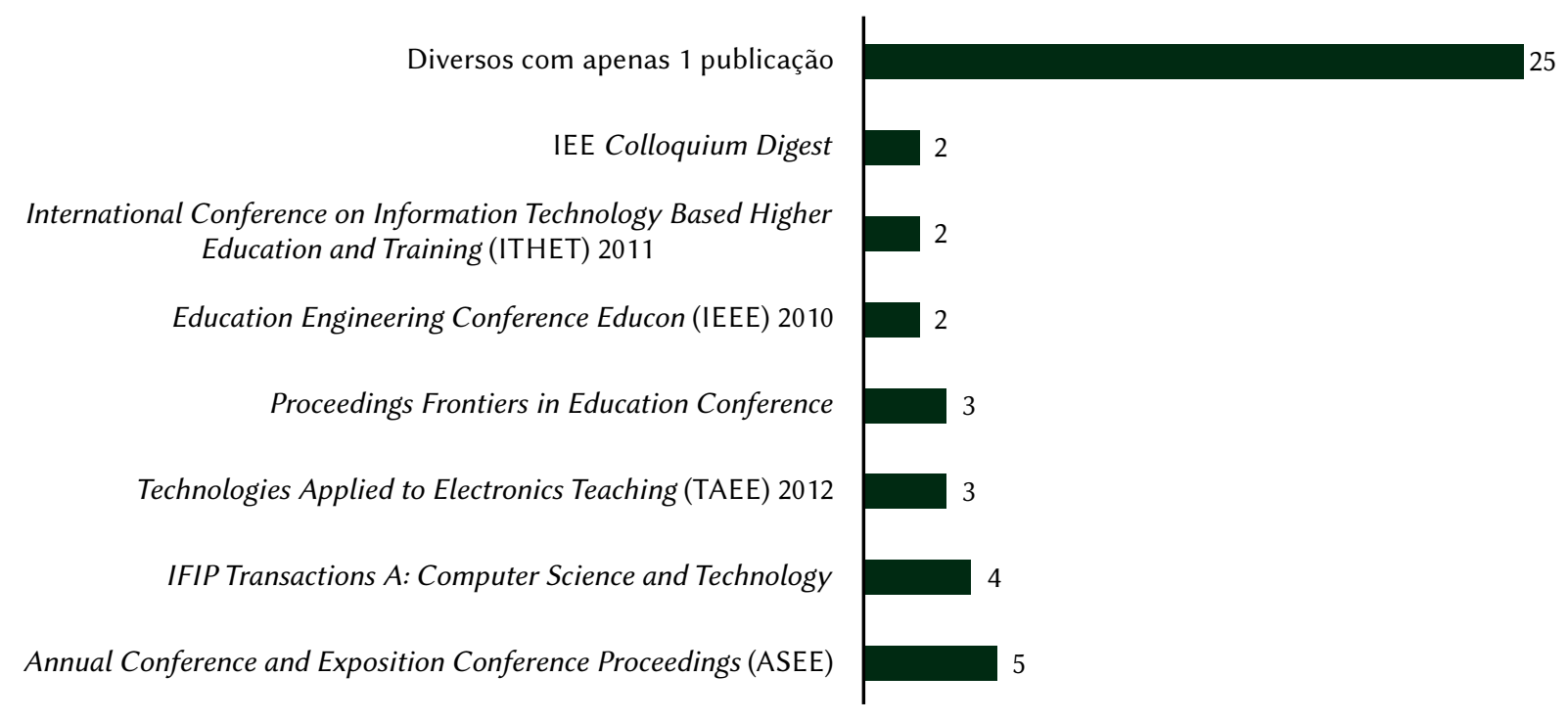

Fonte: Das autoras (2014) 
Dando continuidade, observou-se ainda as publicações quanto à relevância de autor. Pode-se perceber que o tema ainda está em construção quanto a um pesquisador de referência para a área, pois apenas dois autores - Chapman (2001-2001) eAbu-Aisheh (2010-2010)-fizeram mais de uma publicação na área. Contudo, observou-se, em análise aprofundada, que ambos autores publicaram o mesmo trabalho em mais de um periódico. $\mathrm{O}$ autor David A. Chapman é da Universidade de Warwick, do Departamento de Física, Reino Unido. O autor Akram Abu-aisheh é professor associado e diretor do departamento ECE, da Universidade de Hartford. Todos os demais autores, num total de 107 pesquisadores, realizaram apenas uma publicação indexada na Scopus. Assim, pode-se inferir que não se tem ainda na área uma expressiva convergência entre os temas comunicação digital e EaD e nem um pesquisador de referência.

O resultado da pesquisa permitiu identificar ainda algumas instituições que se destacam no âmbito da pesquisa. São quatro: a primeira - University of Hartord - se destaca com três publicações; na sequência têm-se a IEEE e a Open University,com duas publicações; e as 50 restantes apresentaram apenas uma publicação na área, como ilustra o gráfico 3, enfatizando mais uma vez a fragilidade desta discussão, também quando analisadas as possíveis instituições de impacto.

\section{Gráfico 3: Instituições com publicações relacionadas à comunicação digital e EaD}

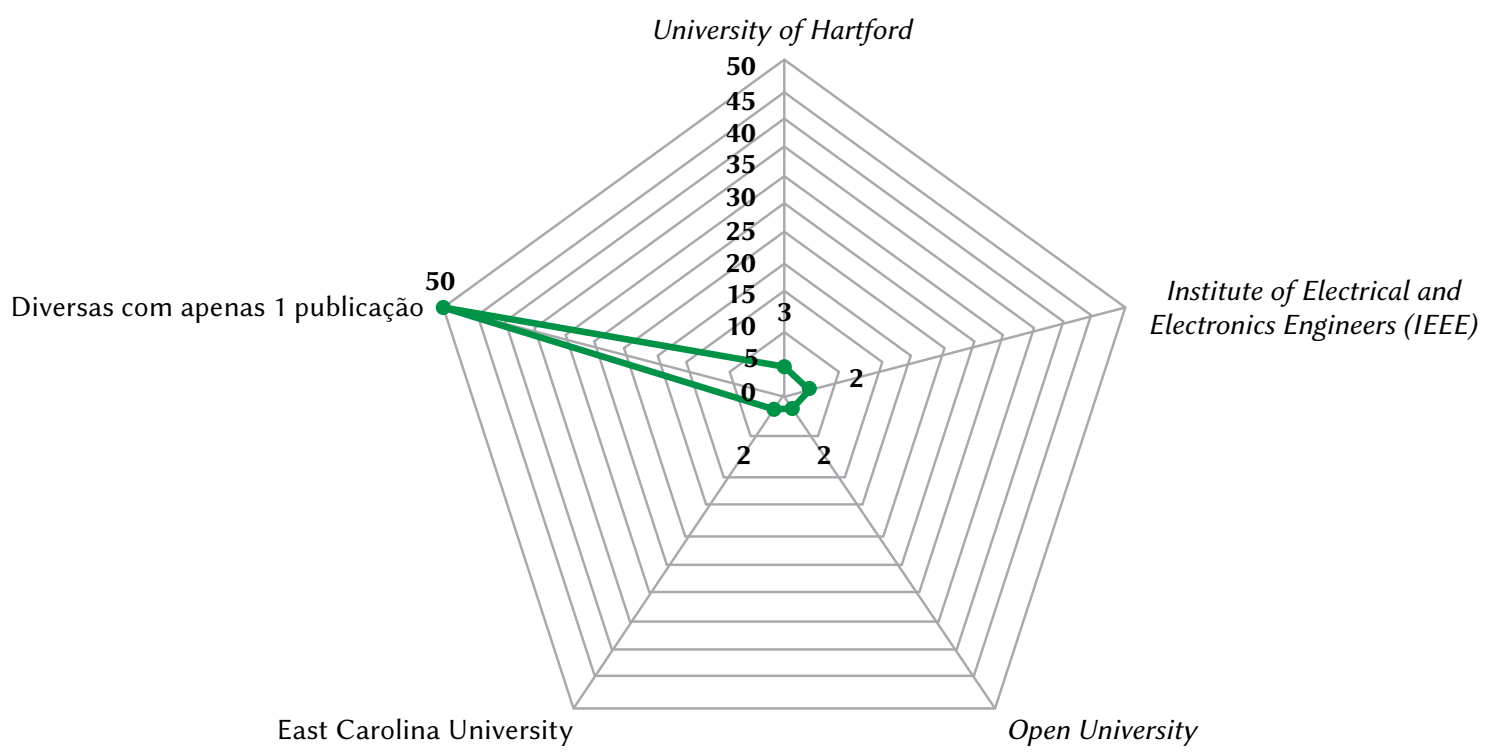

Fonte: Das autoras (2014)

Percebe-se, com base na análise do resultado da pesquisa, como mostra o gráfico 4 , que a publicação na área ganha destaque nos Estados
Unidos, com 15 publicações, quando comparado aos demais países, como: Brasil, Canadá, França, Coreia do Sul, Austrália etc. 


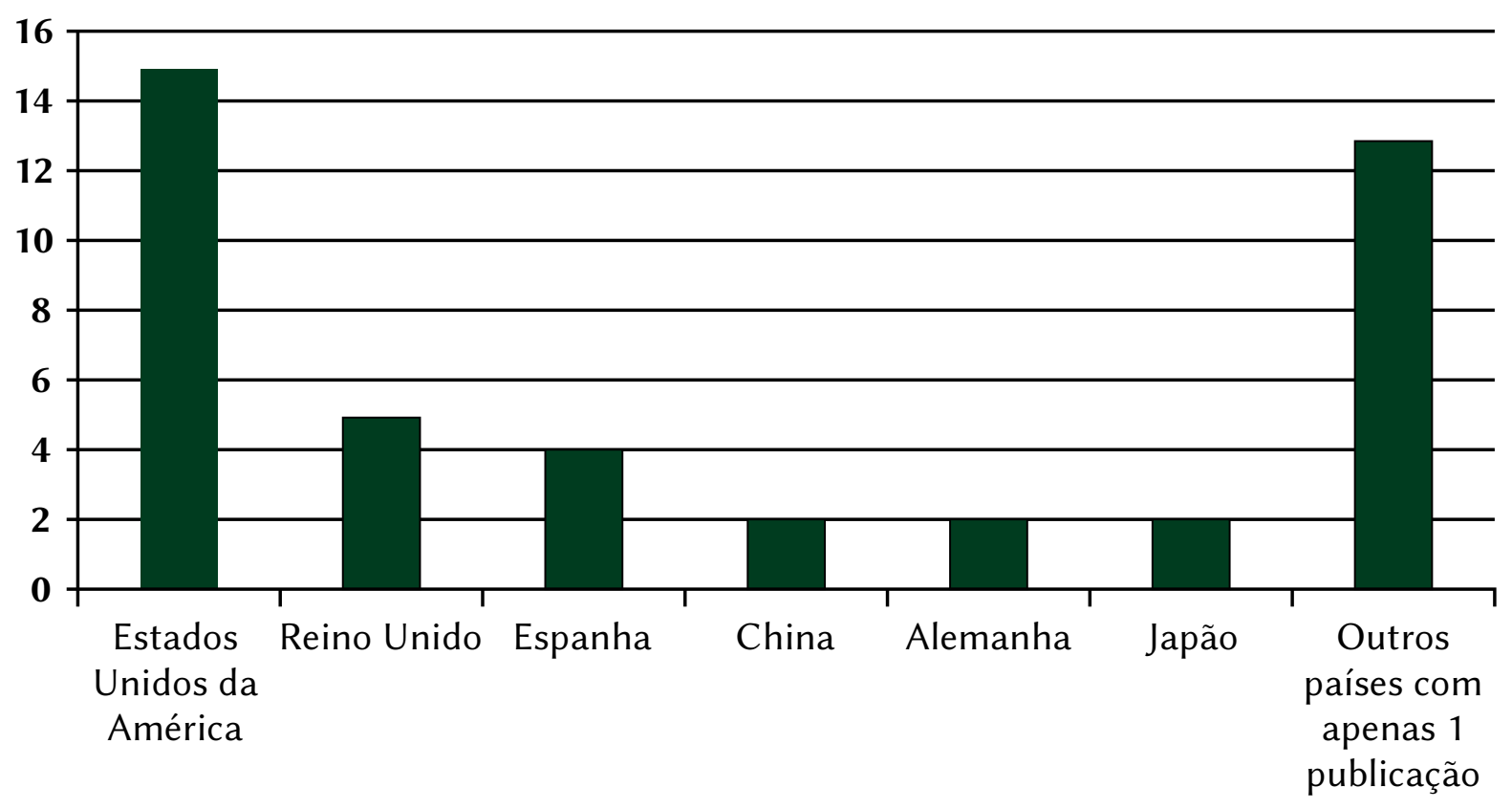

Fonte: Das autoras (2014)

Por fim, foram identificadas as expressões de maior frequência, ao se tratar da relação da comunicação digital com a $\mathrm{EaD}$, a saber: sistema de comunicação digital, Educação a Distância, comunicação digital, currículo, educação, educação da computação, instrução assistida por computador, sistema de aprendizagem, educação de Engenharia, estudante, ensino, sistemas de comunicação, tecnologia da informação,comunicação de dados, sistemas de comunicação, comunicação, disseminação da informação,serviços de informação, sistemas de computador interativos, laboratórios, sociedades einstituições, interfaces de usuário,variando em índices de frequência entre 39 vezes para o primeiro e cinco vezes para os últimos. Para melhor visualização dessa análise, elaborou-se a figura 2 .

Figura 2: Nuvem de tags a partir dos temas mais publicados

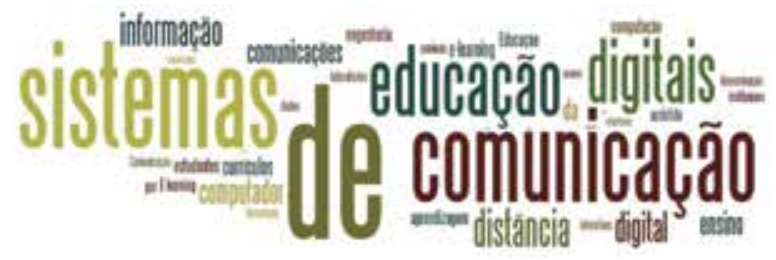

Fonte: Das autoras (2014) 


\subsubsection{Discussão conceitual}

A partir da análise bibliométrica dos dados, resultante da uma busca sistemática da literatura online, disponível na base de dados Scopus, a pesquisa avançou no sentido de discutir conceitualmente o resultado convergente com a problemática deste artigo. Para tanto, utilizouse, além do EndNoteWeb (software de gerenciamento de referência), um software de planilha eletrônica para organização e sistematização dos resultados analisados em profundidade.

A amostra inicial abarca 46 pesquisas científicas. Dessas excluem-se dois trabalhos que apareceram sem autoria definida, eram revisões de conferência. Dos 44 trabalhos, identificou-se a existência de duplicação de dois deles, a situação ocorreu de modo similar em que os dois trabalhos aparecem publicados em journale em conferência, simultaneamente, resultando em 42 trabalhos. Desses, optou-se por analisar os classificados como artigo e paper de conferência, por serem essas as publicações encontradas com maior frequência, além de frequentemente oferecerem acesso remoto, sem restrição de reserva, para domínio público, o que deu uma amostra efetiva para análise de 37 trabalhos a serem analisados em maior profundidade a partir de critérios previamente definidos, a saber: análise do título; do resumo; disponibilidade de acesso livre; e real relevância do estudo para a problemática aqui proposta - convergência da comunicação digital com a EaD.

Com base na leitura dos títulos, 31 dos 37 trabalhos foram considerados como possivelmente relevantes para o estudo. Dessa amostra, fez-se a leitura dos resumos, em que se identificou 15 trabalhos com potencial aderência à pergunta de pesquisa. E 11 destes, ao se buscar documentos disponíveis nas bases de dados online, efetivaram-se como amostra real para leitura completa e aprofundada sobre o tema. Destes observou-se que somente nove, como ilustra a tabela 2, apresentam real contribuição com a discussão aqui proposta.

Tabela 2: Seleção dos artigos encontrados na busca

\begin{tabular}{|l|c|}
\hline Total de trabalhos encontrados & 46 \\
\hline Trabalhos sem autores & 44 dos 46 (excluídos 2) \\
\hline Trabalhos duplicados & 42 dos 44 (excluídos 2) \\
\hline Artigos e Papers de conferência & 37 dos 42 (excluídos 5) \\
\hline Relevância pelo título & 31 dos 37 (excluídos 6) \\
\hline Relevância do resumo & 15 dos 31 (excluídos 16) \\
\hline Disponíveis para download & 11 dos 15 (indisponível 4) \\
\hline Relevância artigo completo & 9 dos 11 (2 excluídos) \\
\hline
\end{tabular}

Fonte: Das autoras (2014) 
A partir da apreciação crítica dos pressupostos teóricos apresentados nos nove trabalhos selecionados, pôde-se perceber que a ênfase da comunicação digital na $\mathrm{EaD}$ é escassa, mas quando intersectam esta relação se dá comumenteem estudosempíricosquefazem menção aos temas emergentes que convergem a partir das tecnologias, como organizado na figura 3.

Figura 3: Mapa conceitual resultante da leitura da convergência da digital com a EaD

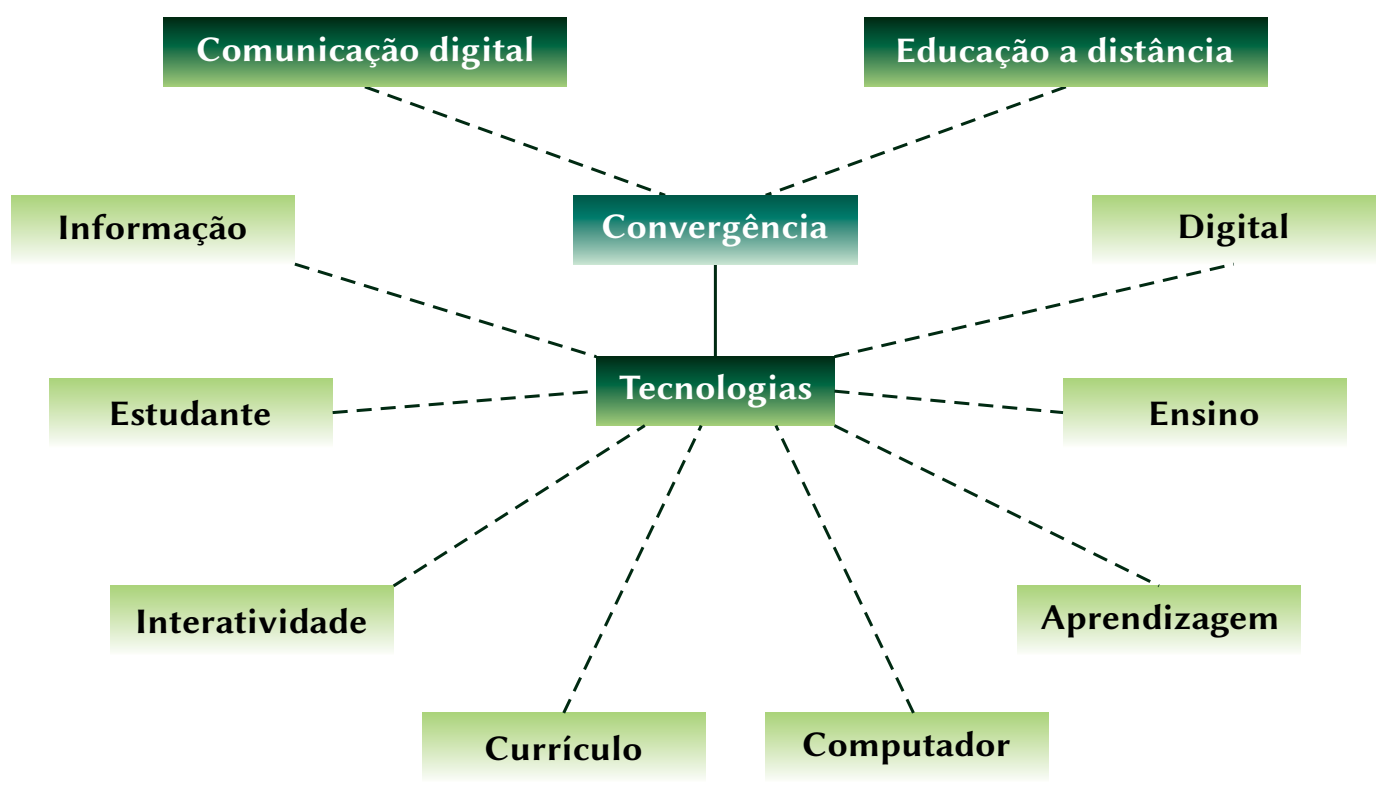

Fonte: Das autoras (2014)

Porém, apesar de ser importante para o contexto dos cursos, na modalidade a distância, não se encontrou nenhum artigo que faça a ligação direta das duas temáticas. Todavia, pode-se identificar, como ilustra a figura 3, que a relação da comunicação digital com a $\mathrm{EaD}$, quando existente indiretamente, está intimamente ligada com o uso das tecnologias e a partir desta intersecção, motivada pelo uso das tecnologias no processo de ensino-aprendizagem, algumas expressões se destacam, a saber: informação, no sentido de disseminar o conhecimento em espaço virtual; estudante,como agente principal neste processo; interatividade, no sentido de aproximar e humanizar o ensinar e aprender; currículo, como elemento transformador no âmbito educacional; computador,como recurso didático pedagógico atrelado às tecnologias digitais; aprendizagem, como resultante do processo de construção do conhecimento; ensino, como forma mediadora para disseminar e compartilhar novos saberes; digital, como elemento que expande o acesso à informação, por meio de diferentes mídias, como: webconferência, hipertexto, computação gráfica, animação.

Por meio das expressões que compõem o mapa conceitual apresentado, percebe-se que a sociedade vive hoje num ambiente complexo, multidisciplinar, multiqualificado, onde as possibilidades de comunicação emergem a cada momento. Assim, considera-se que um programa de educação deve assumir um novo modo de fazer pedagógico. Um modo que seja dinâmico sustentado por um programa de ação consistente e congruente que se movimenta com base nos recursos de tecnologias de comunicação digital, em que as palavras mapeadas devem fazer parte desse cenário. 


\section{CONSIDERAÇÕES FINAIS}

As transformações impulsionadas pelo uso intensivo das tecnologias proporcionam um novo modo de se comunicar implicando a organização de uma sociedade em rede,conectada em diferentes espaços que desafiam o ensinar e aprender propostos pela escola tradicional. Exige-se um novo modo atual e real que seja capaz de atender à necessidade atual.

A partir dessa observação, considera-se que um novo modelo de educação precisa centrar-se em três questões fundamentais: quem educamos? Para que educamos? Quem queremos formar? A partir desses questionamentos é necessário ensinar de modo a se construir significado, para que o conhecimento se constitua em rede deixando de ser um elemento isolado e passe a ser difuso, rizomático, interconectado e interdisciplinar.
Porisso o aprendere o ensinar mediados por tecnologias, principalmente as digitais, podem ser considerados um processo natural. Considerase que a tecnologia é um fator que implica um novo modo de fazer educação. Repensar um novo modelo educacional, mais especificamente na modalidade a distância, exige a utilização de diferentes meios para promover a comunicação significativa, contribuindo para promover espaços que convergem para uma nova cultura.

Tudo isso levanta e indica a necessidade da ampliação de estudos nessa área. Estudos que vislumbrem esta interseção à luz de outro modo de fazer educação em que o espaço e o tempo tomam outra dimensão, se tornam secundários no processo, e o foco passa a ser a intensidade de espaço e de tempo, outro conceito que não está sendo explorado.Concluindo, sugere-se a ampliação deste estudo perquirindo o sentido ontológico e afluência conceitual e de uso da comunicação digital e as suas implicações com a prática para uma nova educação - a educação virtual, que pode sim ter como lastro desafiador a Educação a Distância com suas características singulares. 


\section{CONVERGENCE BETWEEN DIGITAL COMMUNICATION AND PRACTICE OF DISTANCE EDUCATION}

\begin{abstract}
Contemporary society is moving in the centre of a reality where disruptive technology is mastering a new way of doing education. A virtual education, in which, communication is present, in different ways andareas, in a movement in technological ascendancy. In this paper the goal is to link digital communication with the practice of distance education. To meet this goal, the methodology used was a bibliometric analysis of scientific literature organized on the basis of online data. As a result we identified the paucity of published empirical and theoretical material that explains the convergence of digitalcommunication with the practice of distanceeducation, thus indicating prominence of the need for research on the ontology of the term "digital communication" and its relation to the practices of another way to do education - ADistance Education.
\end{abstract}

Key-words: Digital

Communication. Distance

Education. Bibliometrics.

\section{REFERÊNCIAS}

ARAUJO, C. A. Bibliometria: evolução histórica e questões atuais. Em Questão, Porto Alegre, v. 12, n. 1, p. 11-32, jan./jun. 2006.

BRASIL. Ministério da Educação e Cultura. Referenciais de qualidade em EaD. 2007. Disponível em: <http://portal.mec.gov.br/seed/ arquivos/pdf/legislacao/refead1.pdf $>$. Acesso em: 18 jun. 2014.

CATAPAN, A. H. O presencial-atual e o presencial-virtual na EaD: construindo um plano de imanência. In: IX Congresso Internacional de Educação a Distância, 2002a, São Paulo. Disponível em: <http://www.abed.org.br/ congresso2002/trabalhos/texto04.htm >. Acesso em: 8 abr. 2014.

Tertium: o novo modo do ser, do saber e do aprender. Actas do VI Congresso Ibero-americano de Informática Educativa. Novembro de 2002b. Vigo (Espanha). Disponível em: <http://lsm.dei.uc.pt/ribie/docfiles/ txt2003731174240paper-168.pdf >. Acesso em: 8 abr. 2014

CUNHA, A. G. da. Dicionário etimológico da língua portuguesa. 4. ed. Rio de Janeiro: Lexikon, 2010.

FEATHER, J.; STURGES, R. P. International Encyclopaedia of Information and Library Science. 2. ed. 2003. Disponível em: <http://api. ning.com/files/svxrPsAClWqmE1PzC8D2fZJ1u EMb6nnJj2EWUh3mcscUb45GWY6GK6a-P5 zrsY6yuB7Io4jhBeBI3XKM4oxjhl1Iq5drIT2/ encyclopediaoflis.pdf $>$. Acesso em: 22 jun. 2014.

KENSKI, V.M. Tecnologias e ensino presencial e a distância. Campinas, SP. Papirus, 2004.

LÉVY, P. O que é o Virtual? São Paulo, Editora 34, 1996. 


\section{SOBRE AS AUTORAS}

MACIAS-CHAPULA, C. A. O papel da informetria e da cienciometria e sua perspectiva nacional e internacional. Ciência Informação.v. 27, n. 2, Brasília, maio/ago., 1998. Disponível em: <http://www.scielo.br/pdf/ci/v27n2/macias.pdf >. Acesso em: 18 jun. 2014.

SANTOS, R. N. M. dos; KOBASHI, N.Y. Bibliometria, cientometria, infometria: conceitos e aplicações. Tendências da Pesquisa Brasileira em Ciência da Informação (TPBCI), Brasília, v. 2, n. 1, p. 155-172, jan./dez. 2009. Disponível em: <http://inseer.ibict.br/ancib/index.phptpbci/ article/view/21/43 >. Acesso em: 18 jun. 2014.

SPINAK, E. Dicionário enciclopédico de bibliometría, cienciometría e informetría. Caracas: UNESCO-CII/II, 1996.

Data de recebimento: 07/09/14

Data de aprovação: 17/12/14

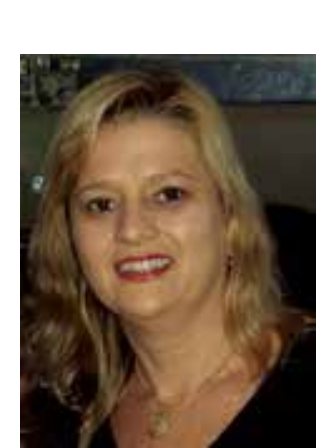

\section{Andréia de Bem}

Machado

Doutoranda no Programa de Pós-graduação em Engenharia e Gestão do Conhecimento, na linha de pesquisa Mídias e Conhecimento. Mestre em Educação CientíficaeTecnológicapela Universidade Federal de Santa Catarina no anode2007.Especialista em Alfabetização também pela UFSC, em 1998. Graduada em Pedagogia na UDESC, em 1994. Atualmente é pesquisadora e professora orientadora do Curso de Especialização Lato Sensu em Ensino em Mídias da Educação, no Curso Ensino de Ciências e no Curso Educação para Diversidade com ênfase em EJA. Linha de Pesquisa: ambiente virtual de ensino-aprendizagem, educação a distância, novas tecnologias, comunicação. 


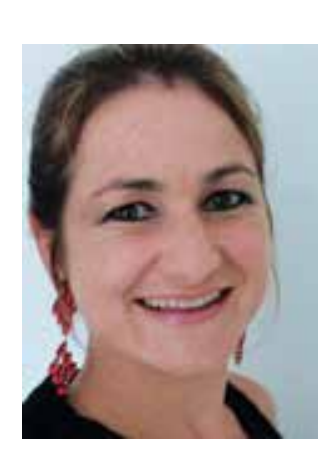

Andreza Regina Lopes da Silva

Doutoranda e mestre em Engenharia e Gestão do Conhecimento pela Universidade Federal de Santa Catarina (UFSC). Administradora pela UFSC no ano de 2002.Especialistaem Educação a Distância pelo SENAC no ano de 2010. Experiência na área de Educação com ênfase em Educação a Distância atuando principalmente nos temas: material didático, projeto,planejamento, desenvolvimento,implementação e avaliação dos cursos a distância. As diferentes atividades desenvolvidas centram-se principalmente como Designer Instrucional (DI) e coordenadora de DI em diferentes projetos. Atualmente desenvolve trabalhos e pesquisas na área de Metodologia, Design Instrucional e Projeto no âmbito da EaD. Pesquisadora CNPq/UFSC, Núcleo PCEADIS - AtelierTCD e Grupo Mídia e Conhecimento. Autora de capítulos de livros e artigos científicos.

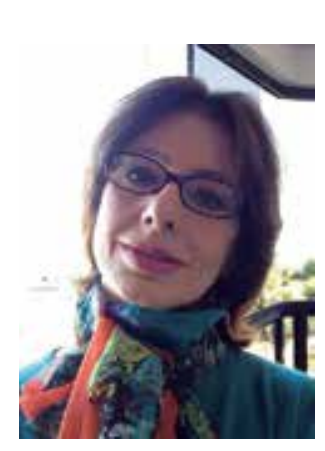

Araci Hack Catapan

Pedagoga e Doutora em Engenharia de Produção pela Universidade Federal de Santa Catarina, na área de Mídia e Conhecimento. Atualmente é professora adjunta da Universidade Federal de Santa Catarina (UFSC). Tem experiência em todos os níveis de Educação. Atua em pesquisa e ensino, com ênfase nos seguintes temas: Educação a Distância $(\mathrm{EaD})$,cibercultura,formação de professores, tecnologia de comunicação digital e objetos de ensino-aprendizagem. Atua nos programas de Pós-graduação da Engenharia e Gestão do Conhecimento e em Educação. É coordenadora do Núcleo de Pesquisa Científica em Educação a Distância CNPq. É coordenadora do Núcleo de Ensino, Pesquisa e Extensão - Atelier TCD: tessituras de linguagens <www.ateliertcd.com.br>. 